\title{
Moral Hazard in the Diamond-Dybvig Model of Banking
}

\author{
David Andolfatto \\ Department of Economics, Simon Fraser University \\ Burnaby, British Columbia, Canada V5A $1 S 6$ \\ Ed Nosal \\ Federal Reserve Bank of Cleveland \\ Cleveland, Ohio, U.S.A. 44101-1387
}

\begin{abstract}
We modify the Diamond-Dybvig [3] model studied in Green and Lin [5] to incorporate a self-interested banker who has a private record-keeping technology. A public record-keeping device does not exist. We find that there is a trade-off between sophisticated contracts that possess relatively good risk-sharing properties but allocate resources inefficiently for incentive reasons, and simple contracts that possess relatively poor risk-sharing properties but economize on the inefficient use of resources. While this trade-off depends on model parameters, we find that simple contracts prevail under a wide range of empirically plausible parameter values. Although moral hazard in banking may simplify the optimal structure of deposit liabilities, this simple structure does not enhance the prospect of bank runs.
\end{abstract}

Key words: banking; private record-keeping; moral hazard; mechanisms; bank runs. 


\section{Introduction $^{1}$}

A distinguishing characteristic of banks is that they issue liabilities predominantly in the form of demandable obligations. The option to redeem bank deposits presumably serves an economic purpose (Diamond and Dybvig [3], Calomiris and Kahn [2]). But potential benefits aside, it is commonly asserted that demandable liabilities open the door to welfare-reducing runs driven by non-fundamental factors. That is, even depositors without any pressing liquidity need may find it privately optimal to exercise the redemption option if they believe - for whatever reason - that others will behave similarly.

Despite its intuitive appeal and alleged empirical relevance, the bank-run phenomenon has proved difficult to rationalize in the context of a formal model. Diamond and Dybvig [3] develop a tractable framework that attempts to do so. However, Green and Lin [5], building on the work of Wallace [8], demonstrate that when the bank is modeled as an optimal allocation mechanism, the prospect of bank-run equilibria in the Diamond-Dybvig environment disappear entirely. Andolfatto, Nosal, and Wallace [1] demonstrate that their result generalizes considerably.

A striking feature of the Green and Lin [5] mechanism is that optimality is achieved under a highly elaborate and unrealistic deposit contract. In particular, the returns to early redemptions vary in a complicated manner on histories of information pertaining to depositor-types, including those depositors who report no pressing liquidity need. While Peck and Shell [7] show that bank-run equilibria may still emerge even in the presence of such sophisticated contracts, it is not obvious that the mechanism that they consider is an optimal one. In any case, it remains true that these sophisticated contracts are not observed in practice. The purpose of our paper is to ask why this might be the case. Specifically, we ask what features of the environment may be responsible for rendering optimal contracts simple and to what extent might these features contribute to our understanding of bank runs.

Both Green and Lin [5] and Peck and Shell [7] have noted the potential role of moral hazard in banking. ${ }^{2}$ Green and Lin [5] state the issue at hand succinctly

1 We would like to thank Ricardo Cavalcanti, Narayana Kocherlakota and the participants at the conference in honor of Neil Wallace. In addition, we received several useful comments from seminar participants at various schools. We would especially like to thank Neil Wallace for many enjoyable hours of conversation regarding money and banking; conversations that greatly influenced the content of this paper. Andolfatto acknowledges the finanical support of SSHRC.

2 Calomiris and Kahn [2] also stress the role of moral hazard in banking. Their analysis differs from the standard Diamond-Dybvig [3] set-up along several dimensions. First, demandability is not desired as a form of consumption insurance; rather, 
as follows:

Another feature of a real banking industry which is absent in our model is the incentive problem of banking executives whose objectives may be different from that of a social planner. Suppose that the mechanism in our model is run by a banker, instead of the planner. The traders report their realized types to the banker who then distributes the resources to the traders, supposedly in the way specified by the mechanism. But, if the traders cannot observe each other's reports, then there is no guarantee that the banker allocates the resources based on the true reported state of nature. The banker might keep part of the endowment for his own consumption and then claim that a great deal of resources has been withdrawn by a number of impatient traders that is larger than is actually the case. Anticipating this possibility and its consequence that less resources will be available at time 1, the patient traders may be tempted to withdraw early, increasing the likelihood of a bank run. Such an incentive problem might be another explanation of why the banking contract in our model is not observed, and why runs have historically occurred.

Following this suggestion, we consider the environment as specified by Green and Lin [5] and modify it by introducing a self-interested banker. Rather than have the mechanism run by the banker, we assume that it is designed by a planner. The banker's comparative advantage over all other agents in the economy is that he possesses a complete and private record-keeping technology concerning all aspects of his banking activities. Furthermore, this technology is superior to any public record-keeping device. This comparative advantage is the source of banker moral hazard in our model. In our analysis, we adopt the extreme view that there is no public record-keeping technology. An implication of this assumption is that while both the planner and banker can observe the reports made by depositors, the planner must "forget" what it has seen in the past. As a result, the planner is compelled to use the banker's version of recorded history to make recommendations regarding payments to depositors.

Even in the context of this relatively simple environment, the analysis becomes increasingly complicated as the number of depositors becomes large. To keep the analysis tractable, we ultimately resort to a special case involving only two depositors. We discover that there is a trade-off between sophisticated contracts that render relatively good risk-sharing properties and simple contracts that economize on the inefficient use of resources. Not surprisingly,

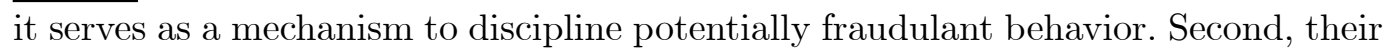
sequential service constraint emerges endogenously for the same purpose. Finally, a 'bank run' in their model corresponds to bank liquidation based on a set of fundamental shocks (information pertaining to the quality of the bank's assets). Others have also stressed moral hazard in determining a bank's capital structure (see Diamond [4] and Krasa and Villamil [6], among others) but do not examine the implications for bank runs. 
this trade-off depends on parameters; but we find that simple contracts prevail under a wide range of empirically plausible parameter values. We find that although the introduction of banker moral hazard may simplify bank contracts, it does not appear to expand the possibility of a bank-run. Indeed, we find that the exact opposite is true.

The paper is organized as follows. In section 2, we describe the environment. Here, we temporarily depart from the standard assumption that depositors possess private information; a simplification that allows us to focus on the moral hazard associated with the banker's informational advantage. We describe mechanisms in section 3. Section 4 describes a special case, the one studied in Green and Lin [5], in which there exists a complete public-recording technology. This optimal allocation in this case serves as a benchmark in what is to follow. Section 5 develops the restrictions that must be placed on any allocation to elicit truth-telling behavior on the part of the banker and section 6 characterizes the optimal allcation. Depositor moral hazard in introduced in section 7 and the implications for bank runs are examined. The paper concludes with section 7 .

\section{The Environment}

The economy is populated by one banker and $N$ depositors, where $N \geq 2$ is a finite integer. There are two dates - date- 1 and date-2 - and one good per date. All agents have access to a constant returns to scale storage technology that converts one unit of date- 1 goods into $R>1$ units of date- 2 goods. Each depositor is endowed with $0<y<\infty$ units of the date-1 good; the banker has no endowment of goods.

A depositor's utility is denoted $U\left(c, c^{\prime}, \omega\right)$, where $c$ is date- 1 consumption, $c^{\prime}$ is date- 2 consumption, and $\omega$ is the depositor's type. Assume that $\omega \in\{p, i\} \equiv \Omega$, where $p$ denotes "patient" and $i$ denotes "impatient." Following Green and Lin [5], preferences are restricted to be:

$$
U\left(c, c^{\prime}, \omega\right)=\left\{\begin{array}{lll}
u\left(c+c^{\prime}\right) & \text { if } \quad \omega=p \\
u(c) & \text { if } \quad \omega=i
\end{array}\right.
$$

where $u(x)=(1-\sigma)^{-1}\left[x^{1-\sigma}-1\right]$ and $\sigma>1$. Hence, a patient depositor views date- 1 and date- 2 consumption as perfect substitutes, while an impatient depositor only values date-1 consumption. The banker has linear preferences defined over his date-2 consumption, which we denote as $b^{\prime}$.

Depositors do not know their type ex ante. Depositor types are generated by an exogenous i.i.d. across depositors process, where realizations occur at 
date- 1 and $0<\pi<1$ denotes the probability that any given depositor is patient. Hence, the probability that $k$ patient depositors are patient, denote

$\Pi_{k}$, is $\Pi_{k}=\left(\begin{array}{l}N \\ k\end{array}\right) \pi^{k}(1-\pi)^{N-k}$, for $k \in\{0,1,2, \ldots, N\} \equiv \mathbb{N}$. There is a second exogenous stochastic process that determines a depositor's place-in-line $n \in$ $\{1,2, \ldots, N\}$ at date- 1 . Assume that any given place-in-line is equally likely for all depositors. Together, these processes determine a date-1 queue $\omega^{N}=$ $\left(\omega_{1}, \omega_{2}, \ldots, \omega_{N}\right)$, where $\omega_{n} \in \Omega$ denotes the type of a depositor with place-inline $n=1,2, \ldots, N$. We will at times refer to $\omega^{N}$ as the state of the world.

Depositors know their own type, $\omega$, but they do not observe $\omega^{N}$ or their placein-line $n$. The depositor's type is observable to the banker, subject to a timing restriction, to be described below.

The timing of events is as follows. First, prior to observing their types, depositors give their endowment to the banker. Nature then selects a queue $\omega^{N} \in \Omega^{N}$ according to the stochastic processes described above. Depositors then interact with the banker at date- 1 sequentially according to their realized place-in-line. The date-1 payouts to depositors are subject to a sequential service constraint; i.e., the date- 1 payout to depositor $\omega_{n}$ can only depend upon type realizations $\omega_{j}, j \leq n$, and cannot depend on subsequent type realizations $\omega_{j}$ for $j>n$. After these $N$ sequential meetings, any remaining output is invested by the banker in the storage technology. The banker then interacts with all depositors simultaneously at date-2, with terminal payouts made at this stage.

Green and Lin [5] make the standard assumption of the existence of a costless and complete public record-keeping technology. We assume that there is no such technology available. The banker, however, is endowed with a costless, complete, and private record-keeping technology. Hence, the banker is able to record all of his interactions and observations concerning all depositors.

\section{Mechanisms}

We consider mechanisms in which the banker's strategy is to make a sequence of $N$ reports at date-1 (one for each depositor) and one report at date- 2 . Associated with each depositor $n>1$, there is a true history of types that we denote $\omega^{n-1}=\left\{\omega_{1}, \omega_{2}, \ldots, \omega_{n-1}\right\} \in \Omega^{n-1}$. There is no history of types for $n=1$, but it will be convenient, in what follows, to denote this "null" history as $\omega^{0}=\Omega^{0} \equiv \varnothing$.

The banker is required to send a report of this history for each depositor. Since the banker is the only agent in the economy that has access to a record keeping device, this history constitutes private information for the banker. Hence, the banker's report associated with depositor $n$ may be an element of 
any conceivable history $\bar{\Omega} \equiv \cup_{j=0}^{N-1} \Omega^{j}$. The banker also makes a date-2 report, which will be described shortly.

The mechanism requires that the banker's date-1 report associated with depositor $n$ be made before the banker observes the depositor's type. The report is made after depositor $n-1$ departs and before depositor $n$ arrives. ${ }^{3}$ Thus, a date-1 strategy for the banker is a set of functions:

$$
m_{n}: \Omega^{n-1} \rightarrow \bar{\Omega} \text { for } n=1,2, \ldots, N .
$$

A date-1 allocation or outcome function for depositors is a recommendation $C_{n}(\cdot)$ made by the mechanism, made contingent on the banker's date- 1 reports and each depositor's type; i.e.,

$$
C_{n}: \bar{\Omega}_{n} \times \Omega_{n} \rightarrow \mathcal{R}_{+} \text {for } n=1,2, \ldots, N
$$

where $\Omega_{n}=\{i, p\}$. Note that the mechanism's date- 1 recommendation is made contingent on the depositor's true type, which is observable by the mechanism, together with the banker's version of the historical record.

The banker's date-2 reporting strategy is a function $m^{\prime}: \Omega^{N} \rightarrow \Omega^{N}$, where the domain represents the set of true histories. At date-2, all depositors reconvene; but since they have no record keeping device at their disposal, they are unable to report the banker's date- 1 announcement, $m_{n}$, or the amount that they consumed at date-1. The planner too has no record-keeping technology; while the planner can observe depositor types at date-2, he cannot observe their place-in-line. Hence, we can summarize the planner's date-2 information with a function $k: \Omega^{N} \rightarrow \mathbb{N}$, where $k\left(\omega^{N}\right)$ reveals the number of patient depositors at date-2. Hence, a date-2 allocation or outcome function for depositors is a recommendation $C_{n}^{\prime}(\cdot)$ made contingent on the banker's date- 2 report and $k\left(\omega^{N}\right)$; i.e.,

$$
C_{n}^{\prime}: \Omega^{N} \times \mathbb{N} \rightarrow \mathcal{R}_{+} \text {for all } n=1,2, \ldots N .
$$

Let $\mathbf{C} \equiv\left\{C_{n}, C_{n}^{\prime}\right\}_{n=1}^{N}$ represent an allocation (for depositors) and let $\mathbf{m} \equiv$ $\left\{m_{n}, m^{\prime}\right\}_{n=1}^{N}$ represent a strategy profile for the banker.

In what follows, we restrict the banker's date- 2 report to be consistent with what the planner can observe at date- 2 ; since the banker would otherwise be making a report that would be known to be false.

Definition 1 The date-2 strategy $m^{\prime}$ is said to be consistent if $k\left(m^{\prime}\left(\omega^{N}\right)\right)=$ $k\left(\omega^{N}\right)$ for all $\omega^{N} \in \Omega^{N}$.

$\overline{3}$ If the mechanism has the banker making his date-1 report after he observes the depositor's type, then it can be easily shown that risk-sharing possibilities are destroyed and autarky will be the only outcome. Such a mechanism cannot be optimal. 
Note that consistency does not imply truth-telling. If consistency is imposed, then we can reduce notation by making the date- 2 allocation solely a function of the banker's consistent date- 2 report. Through a slight abuse of notation, we now let $C_{n}^{\prime}: \Omega^{N} \rightarrow \mathcal{R}_{+}$for all $n=1,2, \ldots N$.

Now fix an allocation $\mathbf{C}$ and a consistent strategy $\mathbf{m}$. Then, conditional on a realization $\omega^{N} \in \Omega^{N}$, the ex post payoff or outcome function for the banker is given by:

$$
B^{\prime}(\mathbf{C}, \mathbf{m}) \equiv R\left[N y-\sum_{n=1}^{N} C_{n}\left(m_{n}\left(\omega^{n-1}\right), \omega_{n}\right)\right]-\sum_{n=1}^{N} C_{n}^{\prime}\left(m^{\prime}\left(\omega^{N}\right)\right)
$$

A mechanism $(\boldsymbol{\Omega}, \mathrm{C})$ is a collection of strategy sets, $\boldsymbol{\Omega}$, and an outcome function, C. The collection of strategy sets is $\Omega=\left(\bar{\Omega}, \Omega^{N}, \Omega_{1}, \ldots, \Omega_{N}\right)$, where $\bar{\Omega}$ and $\Omega^{N}$ represents the banker's date- 1 and date- 2 strategy sets, respectively; and $\Omega_{n}, n=1, \ldots, N$ represent the depositors' type set. Note that we do not include the outcome function for the banker in the definition of a mechanism since, for any given allocation $\mathbf{C}$, the banker's payoff is determined residually from (2).

Definition $\mathbf{2}$ The strategy profile $\mathbf{m}$ for mechanism $(\boldsymbol{\Omega}, \mathbf{C})$ is said to be feasible if:

$$
B^{\prime}(\mathbf{C}, \mathbf{m}) \geq 0
$$

for all $\omega^{N} \in \Omega^{N}$.

Let $\mathcal{M}(\boldsymbol{\Omega}, \mathbf{C})$ denote the set of feasible and consistent strategy profiles that are available to the banker for mechanism $(\boldsymbol{\Omega}, \mathbf{C})$. We are effectively imposing a form of commitment on the banker by requiring him to choose his strategy profile $\mathbf{m} \in \mathcal{M}(\boldsymbol{\Omega}, \mathbf{C})$. Since the economy is finite, some form of commitment must be imposed on the banker; otherwise, he would simply refuse to make any date- 1 pay outs and would consume $R N y$ output in date- 2 . We assume that the banker can commit to make pay outs consistent with his announcements; this implies that $\mathbf{m} \in \mathcal{M}(\boldsymbol{\Omega}, \mathbf{C})$.

Definition 3 The strategy profile $\mathbf{m}^{*} \in \mathcal{M}(\boldsymbol{\Omega}, \mathbf{C})$ constitutes an equilibrium if:

$$
E_{\omega^{N} \in \Omega^{N}}\left[B^{\prime}\left(\mathbf{C}, \mathbf{m}^{*}\right)\right] \geq E_{\omega^{N} \in \Omega^{N}}\left[B^{\prime}(\mathbf{C}, \mathbf{m})\right]
$$

for all $\mathbf{m} \in \mathcal{M}(\boldsymbol{\Omega}, \mathbf{C})$.

Note that our definition of equilibrium satisfies the notion of sequential rationality for the banker even though the banker's expected payoff in (4) is calculated in an ex ante sense. To see this, suppose the proposed equilibrium strategy profile for the banker $\mathbf{m}^{*}$ satisfies (4). Now, consider some history $\hat{\omega}^{n} \in \Omega^{n}$ and suppose that the banker can increase his expected payoff relative 
to the proposed equilibrium by playing the feasible and consistent continuation strategy $\hat{\mathbf{m}}^{n}$ for the remainder of the game. Define a new strategy $\mathbf{m}$ that is identical to $\mathbf{m}^{*}$ for all histories, except following history $\hat{\omega}^{n}$, where the continuation strategy $\hat{\mathbf{m}}^{n}$ is played instead. Clearly then, $\mathbf{m}^{*}$ cannot be an equilibrium strategy since the constructed strategy $\mathbf{m} \in \mathcal{M}(\Omega, \mathbf{C})$ violates inequality (4).

If strategy $\mathbf{m} \in \mathcal{M}(\boldsymbol{\Omega}, \mathbf{C})$ is an equilibrium, then associated with each state $\omega^{N} \in \Omega^{N}$ are payoff functions to depositors $\mathbf{c}=\left\{c_{n}, c_{n}^{\prime}\right\}_{n=1}^{N}$, where $c_{n}\left(\omega^{n}\right) \equiv$ $C_{n}\left(m_{n}\left(\omega^{n-1}\right), \omega_{n}\right)$ and $c_{n}^{\prime}\left(\omega^{N}\right)=C_{n}^{\prime}\left(m^{\prime}\left(\omega^{N}\right)\right)$; together with a banker payoff function $b^{\prime}\left(\mathbf{c}, \omega^{N}\right)$, where $b^{\prime}\left(\mathbf{c}, \omega^{N}\right) \equiv B^{\prime}\left(\mathbf{C}, \mathbf{m}\left(\omega^{N}\right)\right)$. Hence, we can construct an alternative mechanism $(\boldsymbol{\Omega}, \mathbf{c})$ such that if $\mathbf{m} \in \mathcal{M}(\boldsymbol{\Omega}, \mathbf{C})$ is an equilibrium for mechanism $(\boldsymbol{\Omega}, \mathbf{C})$, then $\mathbf{t} \in \mathcal{M}(\boldsymbol{\Omega}, \mathbf{c})$ is an equilibrium for mechanism $(\boldsymbol{\Omega}, \mathbf{c})$, where $\mathbf{t}$ is defined as the truth-telling strategy $t_{n}\left(\omega^{n-1}\right) \equiv \omega^{n-1}$ for all $n=1,2, . ., N$ and $t^{\prime}\left(\omega^{N}\right) \equiv \omega^{N}$.

Definition 4 An allocation $\mathbf{c}$ is said to be truthfully implementable as an equilibrium for mechanism $(\boldsymbol{\Omega}, \mathbf{c})$ if $\mathbf{t} \in \mathcal{M}(\boldsymbol{\Omega}, \mathbf{c})$ is a truth-telling strategy and

$$
E_{\omega^{N} \in \Omega^{N}}\left[b^{\prime}\left(\mathbf{c}, \omega^{N}\right)\right] \geq E_{\omega^{N} \in \Omega^{N}}\left[b^{\prime}\left(\mathbf{c}, \mathbf{m}\left(\omega^{N}\right)\right)\right]
$$

for all $\mathbf{m} \in \mathcal{M}(\Omega, \mathbf{c})$.

In what follows, we can, without loss of generality, restrict attention to allocations that are truthfully implementable.

Under a truth-telling strategy $\mathbf{t}$ for mechanism $(\boldsymbol{\Omega}, \mathbf{c})$, the ex ante utility payoff for depositors is given by:

$$
W(\mathbf{c})=\sum_{\omega^{N} \in \Omega^{N}} \operatorname{Pr}\left(\omega^{N}\right)\left[\sum_{n=1}^{N} U\left(c_{n}\left(\omega^{n-1}, \omega_{n}\right), c_{n}^{\prime}\left(\omega^{N}\right), \omega_{n}\right)\right] .
$$

Definition 5 An optimal allocation $\mathbf{c}$ maximizes $W(\mathbf{c})$ subject to: $[1] b^{\prime}\left(\mathbf{c}, \omega^{N}\right) \geq$

0 for all $\omega^{N} \in \Omega^{N}$ [feasibility]; and [2] $E_{\omega^{N} \in \Omega^{N}}\left[b^{\prime}\left(\mathbf{c}, \omega^{N}\right)\right] \geq E_{\omega^{N} \in \Omega^{N}}\left[b^{\prime}\left(\mathbf{c}, \mathbf{m}\left(\omega^{N}\right)\right)\right]$ for all $\mathbf{m} \in \mathcal{M}(\Omega, \mathbf{c})$ [equilibrium].

\section{Complete Public Record}

In this section, we consider the bench-mark case in which there is a complete public record. The resulting allocation corresponds to that of Green and Lin [5]. We will refer to this allocation as the first-best allocation as there are no informational asymmetries in a complete public record environment.

Since there is a complete public record, the mechanism need not rely on the 
banker's private record keeping device. Equivalently, we can just assume here that the bank automatically adopts a truth-telling strategy. Hence, the firstbest allocation maximizes $W(\mathbf{c})$ subject to feasibility only; i.e., $b^{\prime}\left(\mathbf{c}, \omega^{N}\right) \geq 0$ for all $\omega^{N} \in \Omega^{N}$.

Owing to the specification of a depositor's utility function (1), a number of properties associated with the first-best allocation immediately emerge. First, since impatient depositors do not value date- 2 consumption, they do not receive any in the first-best allocation, i.e., $c_{n}^{\prime}\left(\omega^{N}\right)=0$ if $\omega_{n}=i$ for all $\omega^{N} \in \Omega^{N}$. Second, since patient depositors view date- 1 and date- 2 consumption as perfect substitutes, but one unit of date-1 consumption can be converted into $R>1$ units of date- 2 consumption, patient depositors do not receive any date- 1 consumption in the first-best contract, i.e., $c_{n}\left(\omega^{n-1}, \omega_{n}\right)=0$ if $\omega_{n}=p$ for all $\omega^{n-1} \in \Omega^{n-1}, n=1, \ldots, N$. And finally, since depositor types are observable and they are risk-averse, optimal risk-sharing implies that patient depositors receive the same levels of date- 2 consumption, independent of their place in line, i.e., $c_{n}^{\prime}\left(\omega^{N}\right)=c_{j}^{\prime}\left(\omega^{N}\right)>0$ for all $n, j$ where $\omega_{n}=\omega_{j}=p$. To better understand other aspects associated with risk-sharing, we solve the above maximization problem explicitly. For this purpose, it will be sufficient to consider the case where $N=2$.

Feasibility implies $c_{2}^{\prime}(i, p)=R\left[2 y-c_{1}(i)\right], c_{1}^{\prime}(p, i)=R\left[2 y-c_{2}(p, i)\right]$ and $c_{2}(i, i)=2 y-c_{1}(i)$. Substituting these conditions into (6) results in the following maximization problem,

$$
\begin{gathered}
\max _{c_{1}(i), c_{2}(p, i)} \pi^{2} 2 u(R y)+(1-\pi) \pi\left\{u\left(c_{1}(i)\right)+u\left(R\left[2 y-c_{1}(i)\right)\right]\right\} \\
+\pi(1-\pi)\left\{u\left(c_{2}(p, i)\right)+u\left(R\left[2 y-c_{2}(p, i)\right]\right)\right\}+ \\
(1-\pi)^{2}\left\{u\left(c_{1}(i)\right)+u\left(2 y-c_{1}(i)\right)\right\} .
\end{gathered}
$$

The date-1 payoffs to impatient depositors are given by:

$$
c_{2}(p, i)=\left[\frac{2 y}{1+A^{1 / \sigma}}\right] ; c_{1}(i)=\left[\frac{2 y}{1+B^{1 / \sigma}}\right] ; c_{2}(i, i)=\left[\frac{2 y B^{1 / \gamma}}{1+B^{1 / \gamma}}\right] .
$$

Since $R>1$ and $\sigma>1$, it follows that $A \equiv R^{1-\sigma}<1$ with $B \equiv[\pi A+1-\pi]<$ $A$. It is straightforward to establish that:

$$
\begin{gathered}
0<c_{2}(i, i)<y<c_{1}(i)<c_{2}(p, i) \\
y<c^{\prime}(p, i)<c^{\prime}(i, p)<R y=c^{\prime}(p, p) .
\end{gathered}
$$

The inequalities above describe the nature of optimal risk-sharing in this environment. In particular, note that in the event that there is only one impatient depositor, this agent receives a date- 1 consumption that exceeds the autarkic 
level $y$; this is evidence of risk-sharing between impatient and patient depositors. Note further that an impatient depositor receives a larger payoff if he is second in line and follows a patient depositor; i.e., $c_{2}(p, i)>c_{1}(i)$. Intuitively, if the first depositor is patient, the planner is better able to share risks with a subsequent impatient depositor and the patient depositor, than if the first depositor is impatient, i.e., in the former case, no payment is made, leaving the banker with greater resources. Although the first impatient depositor receives an amount in excess of $y$, if the second depositor turns out to be impatient, he will receive a date-1 payoff that falls below the autarkic level.

As $N$ becomes large, the date- 1 payoffs to impatient depositor $n$ associated with the first-best allocation becomes a complicated function of the history $\omega^{n-1}$. One motivation for our paper was the conjecture that this complicated allocation structure is an artifact of the assumption that the banker is a benevolent agent. We now explore the validity of this conjecture.

\section{Incentive-Feasible Allocations}

Before we characterize the set of incentive-feasible allocations in the absence of a public record, it is instructive to demonstrate that the first-best allocation cannot be truthfully implemented as an equilibrium. To see this, note that the truth-telling strategy $\left(t_{1}, t_{2}\right)=\left(\varnothing, \omega_{1}\right), t^{\prime}=\omega^{2}$ delivers a zero payoff to the banker under every realization $\omega^{2}$. Consider the following deviation $\left(m_{1}, m_{2}\right)=$ $\left(i, \omega_{1}\right), m^{\prime}=\omega^{2}$. That is, the banker announces to the first depositor that he is second in line and that the previous depositor was impatient and thereafter tells the truth. Since $m^{\prime}=t^{\prime}$, the deviant strategy is consistent.

We now check to see if the banker's new strategy is feasible and profitable. If the state of the world turns out to be either $\omega^{2}=(p, i)$ or $\omega^{2}=(p, p)$, then the first depositor will receive a zero payoff. Since the banker announces the truth after the first depositor in line, all depositors will receive their first-best allocation payoffs; this outcome is feasible since the banker's payoff is zero. If the state of the world turns out to be $\omega^{2}=(i, i)$ or $\omega^{2}=$ $(i, p)$, then the first depositor receives the payoff $c_{2}(i, i)$, instead of $c_{1}(i)>$ $c_{2}(i, i)$. In both cases the resource constraints are satisfied since, in the former, $R\left[2 y-c_{2}(i, i)\right]-c^{\prime}(i, p)>R\left[2 y-c_{1}(i)\right]-c^{\prime}(i, p)=0$, and in the latter, $2 y-c_{2}(i, i)-c_{2}(i, i)>2 y-c_{1}(i)-c_{2}(i, i)=0$. In both cases, the banker receives a strictly positive date- 2 payoff. Since the banker's deviant strategy is both feasible and consistent, and provides a higher expected payoff than truth-telling, the first-best allocation cannot be an equilibrium outcome.

We now characterize the set of feasible allocations that elicit truth-telling. To keep matters simple, we restrict attention to the case in which $N=2$, in which 
case there are four possible states of the world, $\omega^{2} \in\{(p, p),(p, i),(i, p),(i, i)\}$. Here, we are interested characterizing the set of incentive-feasible allocations for the direct revelation mechanism $(\Omega, \mathbf{c})$. To do this, we work recursively, starting with date-2 announcements.

\subsection{Date-2}

Consider first the states $\omega^{2}=(p, p)$ and $\omega^{2}=(i, i)$. In these states, the banker will announce $m^{\prime}=(p, p)$ and $m^{\prime}=(i, i)$, respectively, because consistency demands it. However, if the state of the world is either $\omega^{2}=(i, p)$ or $\omega^{2}=(p, i)$, consistency requires only that the banker's announcement satisfy $k(i, p)=k(i, p)=1$, i.e., the banker's announcement contains one $i$ and one $p$. Independent of what has happened in the past, the banker maximizes his payoff by minimizing the required date- 2 payout to depositors. If the state of the world is $\omega^{2}=(p, i)$, then truth-telling requires,

$$
c_{1}^{\prime}(p, i)+c_{2}^{\prime}(p, i) \leq c_{1}^{\prime}(i, p)+c_{2}^{\prime}(i, p)
$$

and if the state of the world is $\omega^{2}=(i, p)$, then truth-telling requires,

$$
c_{1}^{\prime}(i, p)+c_{2}^{\prime}(i, p) \leq c_{1}^{\prime}(p, i)+c_{2}^{\prime}(p, i)
$$

Together, these two conditions imply,

$$
c_{1}^{\prime}(p, i)+c_{2}^{\prime}(p, i)=c_{1}^{\prime}(i, p)+c_{2}^{\prime}(i, p)
$$

For notational convenience, define $X \equiv c_{1}^{\prime}(i, p)+c_{2}^{\prime}(i, p)$.

Let $b^{\prime}\left(\omega^{2}\right)$ denote the banker's payoff associated with truth-telling for a feasible allocation in state $\omega^{2}$; i.e.,

$$
\begin{aligned}
& b^{\prime}(p, p)=R\left[2 y-c_{1}(p)-c_{2}(p, p)\right]-c_{1}^{\prime}(p, p)-c_{2}^{\prime}(p, p) \geq 0 \\
& b^{\prime}(p, i)=R\left[2 y-c_{1}(p)-c_{2}(p, i)\right]-X \geq 0 \\
& b^{\prime}(i, p)=R\left[2 y-c_{1}(i)-c_{2}(i, p)\right]-X \geq 0 \\
& \left.b^{\prime}(i, i)=R\left[2 y-c_{1}(i)-c_{2}(i, i)\right]\right)-c_{1}^{\prime}(i, i)-c_{2}^{\prime}(i, i) \geq 0 .
\end{aligned}
$$

In what follows, we will restrict attention to feasible, truth-telling allocations that provide some risk-sharing features for depositors; since otherwise, autarky would be preferred by depositors. In particular, we assume that:

$$
c_{2}(p, i) \geq c_{1}(i)>y>c_{2}(i, i)
$$


Since condition (7) completely characterizes truth-telling at date-2, we now move back to date- 1 and characterize the restrictions that imply truth-telling beginning with the last depositor in line, and then the first.

\subsection{Date-1}

We provide conditions for truth-telling starting with the second depositor in line, moving next to the first depositor in line. Beginning with the second depositor, it is sufficient to assume that the banker has at this point told the truth to the first depositor; i.e., $m_{1}=\varnothing$. Conditional on this being the case, we must then consider the banker's problem for each conceivable history $\omega^{1} \in\{i, p\}$. Of course, since condition (7) is assumed to hold, the banker will always weakly prefer to tell the truth at date- 2 .

\subsubsection{Depositor 2: History $\omega^{1}=p$}

Conditional on the banker having announced $m_{1}=\varnothing$, having then observed $p$, and having paid out $c_{1}(p)$, the banker is now in a position to make one of three reports $m_{2} \in\{\varnothing, i, p\}$. The expected payoff to $m_{2}=p$ is given by:

$$
\begin{aligned}
& \pi\left\{R\left[2 y-c_{1}(p)-c_{2}(p, p)\right]-c_{1}^{\prime}(p, p)-c_{2}^{\prime}(p, p)\right\} \\
& +(1-\pi)\left\{R\left[2 y-c_{1}(p)-c_{2}(p, i)\right]-X\right\}
\end{aligned}
$$

The expected payoff to $m_{2}=\varnothing$ is given by:

$$
\begin{aligned}
& \pi\left\{R\left[2 y-c_{1}(p)-c_{1}(p)\right]-c_{1}^{\prime}(p, p)-c_{2}^{\prime}(p, p)\right\} \\
& +(1-\pi)\left\{R\left[2 y-c_{1}(p)-c_{1}(i)\right]-X\right\}
\end{aligned}
$$

The expected payoff to $m_{2}=i$ is given by:

$$
\begin{aligned}
& \pi\left\{R\left[2 y-c_{1}(p)-c_{2}(i, p)\right]-c_{1}^{\prime}(p, p)-c_{2}^{\prime}(p, p)\right\} \\
& +(1-\pi)\left\{R\left[2 y-c_{1}(p)-c_{2}(i, i)\right]-X\right\}
\end{aligned}
$$

By construction, truth-telling is always feasible. However, any given lie may or may not be feasible. If these lies are feasible, then by comparing the three payoffs above, the solution to the banker's problem entails minimizing the expected payout to the second depositor, i.e.,

$$
\min \left\{\begin{array}{c}
\pi c_{2}(p, p)+(1-\pi) c_{2}(p, i) \\
\pi c_{1}(p)+(1-\pi) c_{1}(i), \pi c_{2}(i, p)+(1-\pi) c_{2}(i, i)
\end{array}\right\} .
$$


Notice that if $c_{2}(p, p)=c_{1}(p)=c_{2}(i, p)=0$ and $c_{2}(p, i) \geq c_{1}(i)>c_{2}(i, i)$, then truth-telling cannot be an equilibrium; this observation is an alternative proof that the first-best allocation is not truthfully implementable.

The choice problem in (13) implies that truth-telling is weakly preferred when the allocation satisfies:

$$
\begin{gathered}
{\left[c_{1}(p)-c_{2}(p, p)\right] \geq\left(\frac{1-\pi}{\pi}\right)\left[c_{2}(p, i)-c_{1}(i)\right]} \\
{\left[c_{2}(i, p)-c_{2}(p, p)\right] \geq\left(\frac{1-\pi}{\pi}\right)\left[c_{2}(p, i)-c_{2}(i, i)\right] .}
\end{gathered}
$$

Conditions (14) and (15), along with the assumed risk-sharing features described in (9), imply that necessary, but not sufficient, conditions for truthtelling at this stage are:

$$
\begin{aligned}
c_{1}(p) & \geq c_{2}(p, p) \geq 0 \\
c_{2}(i, p) & >c_{2}(p, p) \geq 0 .
\end{aligned}
$$

Note that conditions (14)-(15) together with (9) imply that $c_{2}(i, p)>c_{1}(p)$.

Lemma 1 If an allocation c satisfies $b^{\prime}(p, p)=0$ in (8), then conditions (16) and (17) are both necessary and sufficient to induce truth-telling, i.e., $m_{2}=p$.

Proof Observe that $b^{\prime}(p, p)=0$ implies:

$$
R\left[2 y-c_{1}(p)-c_{2}(p, p)\right]-c_{1}^{\prime}(p, p)-c_{2}^{\prime}(p, p)=0 .
$$

In the event that the second depositor is patient, $m_{2}=\varnothing$ and $m_{2}=i$ generate the ex post payoffs

$$
\begin{array}{r}
R\left[2 y-c_{1}(p)-c_{1}(p)\right]-c_{1}^{\prime}(p, p)-c_{2}^{\prime}(p, p) \leq 0 \\
R\left[2 y-c_{1}(p)-c_{2}(i, p)\right]-c_{1}^{\prime}(p, p)-c_{2}^{\prime}(p, p)<0,
\end{array}
$$

respectively, where the weak inequalities following from (16) and (17). Hence, announcing $m_{2}=i$ violates feasibility and announcing $m_{2}=\varnothing$ does not increase the expected payoff to the banker and may violate feasibility.

\subsubsection{Depositor 2: History $\omega^{1}=i$}

We now repeat the above exercise, but supposing instead that the first depositor is impatient. Conditional on the banker having announced $m_{1}=\varnothing$, having then observed $i$, and having paid out $c_{1}(i)$, the banker is now in a position to make one of three reports $m_{2} \in\{\varnothing, i, p\}$. The expected payoff to $m_{2}=i$ is given by: 


$$
\begin{aligned}
& \pi\left\{R\left[2 y-c_{1}(i)-c_{2}(i, p)\right]-X\right\} \\
& +(1-\pi)\left\{R\left[2 y-c_{1}(i)-c_{2}(i, i)\right]-c_{1}^{\prime}(i, i)-c_{2}^{\prime}(i, i)\right\} .
\end{aligned}
$$

The expected payoff to $m_{2}=\varnothing$ is given by:

$$
\begin{aligned}
& \pi\left\{R\left[2 y-c_{1}(i)-c_{1}(p)\right]-X\right\} \\
& +(1-\pi)\left\{R\left[2 y-c_{1}(i)-c_{1}(i)\right]-c_{1}^{\prime}(i, i)-c_{2}^{\prime}(i, i)\right\} .
\end{aligned}
$$

The expected payoff to $m_{2}=p$ is given by:

$$
\begin{aligned}
& \pi\left\{R\left[2 y-c_{1}(i)-c_{2}(p, p)\right]-X\right\} \\
& +(1-\pi)\left\{R\left[2 y-c_{1}(i)-c_{2}(p, i)\right]-c_{1}^{\prime}(i, i)-c_{2}^{\prime}(i, i)\right\} .
\end{aligned}
$$

If these lies are feasible, then, by comparing the three payoffs above, the solution to the banker's problem entails minimizing the expected payout to the second depositor, i.e.,

$$
\min \left\{\begin{array}{c}
\pi c_{2}(i, p)+(1-\pi) c_{2}(i, i) \\
\pi c_{1}(p)+(1-\pi) c_{1}(i), \pi c_{2}(p, p)+(1-\pi) c_{2}(p, i)
\end{array}\right\}
$$

The choice problem in (21) implies that truth-telling is weakly preferred when the allocation satisfies:

$$
\begin{gathered}
{\left[c_{2}(i, p)-c_{1}(p)\right] \leq\left(\frac{1-\pi}{\pi}\right)\left[c_{1}(i)-c_{2}(i, i)\right]} \\
{\left[c_{2}(i, p)-c_{2}(p, p)\right] \leq\left(\frac{1-\pi}{\pi}\right)\left[c_{2}(p, i)-c_{2}(i, i)\right] .}
\end{gathered}
$$

These two conditions assume that lying is feasible. As it turns out, one can demonstrate the following result.

Lemma 2 If an allocation $\mathbf{c}$ satisfies $b^{\prime}(i, i)=0$ in (8), then the risk-sharing conditions (9) are sufficient to induce truth-telling, i.e., $m_{2}=i$.

Proof Observe that $b^{\prime}(i, i)=0$ implies:

$$
\left.R\left[2 y-c_{1}(i)-c_{2}(i, i)\right]\right)-c_{1}^{\prime}(i, i)-c_{2}^{\prime}(i, i)=0 .
$$

In the event that the second depositor is impatient, $m_{2}=\varnothing$ and $m_{2}=p$ generate the ex post payoffs,

$$
\begin{array}{r}
R\left[2 y-c_{1}(i)-c_{1}(i)\right]-c_{1}^{\prime}(i, i)-c_{2}^{\prime}(i, i)<0 \\
R\left[2 y-c_{1}(i)-c_{2}(p, i)\right]-c_{1}^{\prime}(i, i)-c_{2}^{\prime}(i, i)<0,
\end{array}
$$


respectively, where the inequalities following from (9). Hence, announcing either $m_{2}=\varnothing$ or $m_{2}=p$ is infeasible.

\subsubsection{Depositor 1}

Assume that a feasible allocation satisfies the truth-telling conditions described above for the second depositor and for all depositors at date-2. Furthermore, consider an allocation such that the conditions in lemmas 1 and 2 are satisfied; in particular, $b^{\prime}(p, p)=b^{\prime}(i, i)=0$.

Now consider the banker's choice problem when faced with the first depositor. At this stage, a truthful bank report entails $m_{1}=\varnothing$, which generates an expected payoff:

$$
\pi^{2} b^{\prime}(p, p)+\pi(1-\pi) b^{\prime}(p, i)+(1-\pi) \pi b^{\prime}(i, p)+(1-\pi)^{2} b^{\prime}(i, i) \geq 0 .
$$

There are two possible defections to consider: $m_{1}=i$ and $m_{1}=p$. Either of these defections will not influence date- 2 truth-telling, since those conditions continue to hold independent of previous announcements. But there is a possibility that either of these defections alter subsequent banker behavior away from truth-telling for depositor 2 at date-1. Recall that lemmas 1 and 2 assume that the banker announced the truth, $m_{1}=\varnothing$, to the first depositor.

We begin by considering the deviation $m_{1}=p$ and assume that truth-telling remains optimal thereafter; we subsequently verify that this will indeed be the case. Let $b^{\prime}\left(\omega^{2} \mid m_{1}\right)$ denote the banker's ex post payoff in state $\omega^{2}$ associated with the announcing $m_{1}$ to the first depositor and announcing the truth thereafter. If announcing $m_{1}=p$ is feasible, then the banker's expected payoff is given by:

$$
\pi^{2} b^{\prime}(p, p \mid p)+\pi(1-\pi) b^{\prime}(p, i \mid p)+(1-\pi) \pi b^{\prime}(i, p \mid p)+(1-\pi)^{2} b^{\prime}(i, i \mid p)
$$

where,

$$
\begin{aligned}
& b^{\prime}(p, p \mid p)=R\left[2 y-c_{2}(p, p)-c_{2}(p, p)\right]-c_{1}^{\prime}(p, p)-c_{2}^{\prime}(p, p) \\
& b^{\prime}(p, i \mid p)=R\left[2 y-c_{2}(p, p)-c_{2}(p, i)\right]-X \\
& b^{\prime}(i, p \mid p)=R\left[2 y-c_{2}(p, i)-c_{2}(i, p)\right]-X \\
& b^{\prime}(i, i \mid p)=R\left[2 y-c_{2}(p, i)-c_{2}(i, i)\right]-c_{1}^{\prime}(i, i)-c_{2}^{\prime}(i, i) .
\end{aligned}
$$

When the allocation $\mathbf{c}$ is characterized by $c_{2}(p, i)=c_{1}(i)>c_{2}(i, i)$ and $c_{1}(p)=c_{2}(p, p)$, it is immediately apparent that each of these payoffs are 
equivalent to the truth-telling payoffs, i.e., compare (26) with (8). Hence, announcing the truth, $m_{2}=\omega^{1}$, to the second depositor following the announcement $m_{1}=p$ is a best response for the banker since announcing $m_{1}=p$ is equivalent to announcing the truth, $m_{1}=\varnothing$. Therefore, if $c_{2}(p, i)=c_{1}(i)>$ $c_{2}(i, i)$ and $c_{1}(p)=c_{2}(p, p)$, the banker weakly prefers truth-telling for the first depositor, so that $m_{1}=\varnothing$.

Consider now the case where $c_{2}(p, i)>c_{1}(i)>c_{2}(i, i)$ and the defection $m_{1}=$ $p$. Suppose that the true state of the world is $\omega^{2}=(i, i)$. The first depositor will receive a payoff $c_{2}(p, i)$. The second depositor will receive: $c_{2}(i, i)$ if the banker announces $m_{2}=i$ (truth); $c_{2}(p, i)$ if the banker announces $m_{2}=p($ lie); or $c_{1}(i)$ if the banker announces $m_{2}=\varnothing$ (lie). Since $c_{2}(i, i)$ is the smallest of these three payments, the banker's best response to the second depositor is to announce $m_{2}=i$. But observe that if $b(i, i)=0$, then $b^{\prime}(i, i \mid p)<0$ since $c_{2}(p, i)>c_{1}(i)$. Therefore, if $b(i, i)=0$, then announcing $m_{1}=p$ is infeasible when $c_{2}(p, i)>c_{1}(i)>c_{2}(i, i)$.

Finally, consider the defection $m_{1}=i$ followed by truth-telling thereafter. In this case, the banker's ex post payoffs are given by:

$$
\begin{aligned}
& b^{\prime}(p, p \mid i)=R\left[2 y-c_{2}(i, p)-c_{2}(p, p)\right]-c_{1}^{\prime}(p, p)-c_{2}^{\prime}(p, p) \\
& b^{\prime}(p, i \mid i)=R\left[2 y-c_{2}(i, p)-c_{2}(p, i)\right]-X \\
& b^{\prime}(i, p \mid i)=R\left[2 y-c_{2}(i, i)-c_{2}(i, p)\right]-X \\
& b^{\prime}(i, i \mid i)=R\left[2 y-c_{2}(i, i)-c_{2}(i, i)\right]-c_{1}^{\prime}(i, i)-c_{2}^{\prime}(i, i) .
\end{aligned}
$$

Note that if $c_{2}(i, p) \leq c_{1}(p)$, then each of these payoffs weakly, and in some cases strictly, dominate the truth-telling payoffs, i.e., compared (27) with (8). Hence, a necessary condition to induce truth-telling is

$$
c_{2}(i, p)>c_{1}(p)
$$

But this conditions implies that

$$
b^{\prime}(p, p \mid i)<b^{\prime}(p, p)
$$

so that if $b^{\prime}(p, p)=0$, then announcement $m_{1}=i$ is infeasible.

\subsection{Section Summary}

Above, we have described the restrictions necessary on any allocation that possesses some degree of risk-sharing to induce truth-telling. These allocations displayed either $c_{2}(p, i)>c_{1}(i)>c_{2}(i, i)$ or $c_{2}(p, i)=c_{1}(i)>c_{2}(i, i)$. For 
convenience, we label the former class of allocations full risk-sharing and the latter class partial risk-sharing.

Under full risk-sharing, the analysis above, i.e., conditions (16), (17) and (28), demonstrate that necessary conditions to induce truth-telling are:

$$
c_{2}(i, p)>c_{1}(p)>c_{2}(p, p) \geq 0
$$

Hence, in order to align banker incentives correctly, some patient depositors will receive some date- 1 consumption. These payments are clearly inefficient relative to the first-best allocation; and the greater these payments, the greater the inefficiency. In addition, if $b(p, p)=b(i, i)=0$, then (29) turns out to be both necessary and sufficient to induce truth-telling (as it renders lying infeasible).

Under partial risk-sharing, the necessary conditions truth-telling are:

$$
c_{2}(i, p)>c_{1}(p)=c_{2}(p, p) \geq 0
$$

Once again, if $b(p, p)=b(i, i)=0$, then these conditions are also sufficient to induce truth-telling. We summarize the main results of this section with the following proposition.

Proposition 1 Under the conditions stated in lemmas 1 and 2, condition (29) is both necessary and sufficient to induce truth-telling behavior under a full risk-sharing allocation and condition (30) is both necessary and sufficient to induce truth-telling behavior under a partial risk-sharing allocation.

We cannot, at this stage, determine whether an optimal allocation is characterized by either full or partial risk-sharing. As it turns out, this will depend on parameters. We now turn to characterizing an optimal allocation.

\section{Optimal Allocations}

Optimal allocations, whether they be characterized by full or partial risksharing, will share a number of common features. Since impatient depositors do not value date- 2 consumption and since none of these consumptions have implications for banker truth-telling, an optimal allocation will set

$$
c_{1}^{\prime}(i, i)=c_{2}^{\prime}(i, i)=c_{1}^{\prime}(i, p)=c_{2}^{\prime}(p, i)=0 .
$$

An implication of this is that date-2 truth-telling constraints in an optimal mechanism simplifies to

$$
c_{1}^{\prime}(p, i)=c_{2}^{\prime}(i, p) \equiv c^{\prime}(p)
$$




\subsection{Partial Risk-Sharing}

A partial risk-sharing solution is characterized by the simple date- 1 withdrawal schedule $c_{2}(p, i)=c_{1}(i)>c_{2}(i, i)$. Above, we established that a necessary condition for truth-telling is $c_{2}(i, p)=\varepsilon>0$. Note that restricting the allocation such that $c_{1}(p)=c_{2}(p, p)=0$ is both efficient and in no way alters this necessary condition. Nor is this necessary condition altered if we further restrict the allocation to minimize the banker's ex post payoffs in the following manner:

$$
\begin{aligned}
& b^{\prime}(p, p)=R 2 y-c_{1}^{\prime}(p, p)-c_{2}^{\prime}(p, p)=0 ; \\
& b^{\prime}(p, i)=R\left[2 y-c_{1}(i)\right]-c^{\prime}(p)=R \varepsilon>0 \\
& b^{\prime}(i, p)=R\left[2 y-c_{1}(i)-\varepsilon\right]-c^{\prime}(p)=0 \\
& \left.b^{\prime}(i, i)=R\left[2 y-c_{1}(i)-c_{2}(i, i)\right]\right)=0 .
\end{aligned}
$$

Hence, it appears that an efficient allocation that respects truth-telling can deliver zero profit to the banker in all states of the world except $\omega^{2}=(i, p)$, where the banker earns $R \varepsilon>0$. Note further that since $b^{\prime}(p, p)=b^{\prime}(i, i)=0$, the condition necessary for truth-telling, $c_{2}(i, p)=\varepsilon$ becomes both necessary and sufficient.

It is straightforward to demonstrate that optimal risk-sharing entails setting $c_{1}^{\prime}(p, p)=c_{2}^{\prime}(p, p)=R y$. Imposing this condition, along with (32), the planner's problem is given by:

$$
\begin{gathered}
W^{P}(\pi, \sigma)=\max _{c_{1}(i)} \pi^{2} 2 u(R y)+ \\
\left.(1-\pi) \pi\left\{u\left(c_{1}(i)\right)+u\left(\varepsilon+R\left[2 y-c_{1}(i)-\varepsilon\right]\right)\right]\right\}+ \\
\pi(1-\pi)\left\{u\left(c_{1}(i)\right)+u\left(R\left[2 y-c_{1}(i)-\varepsilon\right]\right)\right\}+ \\
(1-\pi)^{2}\left\{u\left(c_{1}(i)\right)+u\left(2 y-c_{1}(i)\right)\right\} .
\end{gathered}
$$

The solution to this problem, $c_{1}(i)$, is characterized by:

$$
\begin{aligned}
{[2 \pi+1-\pi] u^{\prime}\left(c_{1}(i)\right)=} & \pi R\left\{u^{\prime}\left(\varepsilon+R\left[2 y-c_{1}(i)-\varepsilon\right]\right)+u^{\prime}\left(R\left[2 y-c_{1}(i)-\varepsilon\right]\right)\right\}+ \\
& (1-\pi) u^{\prime}\left(2 y-c_{1}(i)\right) .
\end{aligned}
$$

Setting $\varepsilon$ sufficiently close to zero so that it can effectively be ignored, the (approximate) solution for the date-1 payments to impatient depositors is 
given by:

$$
c_{2}(p, i)=c_{1}(i)=\left[\frac{1}{1+D^{1 / \sigma}}\right] 2 y>c_{2}(i, i)=\left[\frac{D^{1 / \sigma}}{1+D^{1 / \sigma}}\right] 2 y
$$

where,

$$
D \equiv\left(\frac{2 \pi R^{1-\sigma}+1-\pi}{2 \pi+1-\pi}\right) \in(0,1)
$$

Note that the date- 1 payment to the patient depositor in state $(i, p)$ vanishes as $\varepsilon \rightarrow 0$, as does the profit earned by the banker. In what follows, we evaluate the (approximate) maximum value of this program $W^{P}(\pi, \sigma)$ for $\varepsilon=0$.

\subsection{Full Risk-Sharing}

A full risk-sharing solution is characterized by the sophisticated date- 1 withdrawal schedule $c_{2}(p, i)>c_{1}(i)>c_{2}(i, i)$. Above, we established that a necessary condition for truth-telling is $c_{2}(i, p)>c_{1}(p)=\eta>0$. Note that restricting the allocation such that $c_{2}(p, p)=0$ is both efficient and in no way alters this necessary condition. Nor is this necessary condition altered if we further restrict the allocation to minimize the bank's ex post payoffs in the following manner:

$$
\begin{aligned}
& b^{\prime}(p, p)=R\left[2 y-c_{1}(p)\right]-c_{1}^{\prime}(p, p)-c_{2}^{\prime}(p, p)=0 \\
& b^{\prime}(p, i)=R\left[2 y-c_{1}(p)-c_{2}(p, i)\right]-c^{\prime}(p)=0 ; \\
& b^{\prime}(i, p)=R\left[2 y-c_{1}(i)-c_{2}(i, p)\right]-c^{\prime}(p)=0 ; \\
& \left.b^{\prime}(i, i)=R\left[2 y-c_{1}(i)-c_{2}(i, i)\right]\right)=0 .
\end{aligned}
$$

Hence, it appears that an efficient allocation that respects truth-telling can deliver zero profit to the banker in all states of the world. Furthermore, since $b^{\prime}(p, p)=b^{\prime}(i, i)=0$, the condition necessary for truth-telling, $c_{2}(i, p)>$ $c_{1}(p)=\eta>0$, becomes both necessary and sufficient.

Note that $b^{\prime}(p, i)=b^{\prime}(i, p)=0$ implies:

$$
c_{2}(p, i)-c_{1}(i)=c_{2}(i, p)-c_{1}(p) .
$$

This condition makes clear the cost associated with full risk-sharing. In particular, $c_{2}(p, i)>c_{1}(i)$ can only come at the expense of increasing date- 1 payments to patient depositors, i.e., $c_{2}(i, p)>c_{1}(p)>0$.

Under the full risk-sharing scenario, the planner's problem can be stated as follows: 


$$
\begin{gathered}
w^{F}(\pi, \sigma)=\max _{c_{2}(p, i), c_{1}(i), c_{1}(p), c_{1}^{\prime}(p, p)} \pi^{2}\left\{u\left(c_{1}(p)+c_{1}^{\prime}(p, p)\right)+u\left(R\left(2 y-c_{1}(p)\right)-c_{1}^{\prime}(p, p)\right)\right\} \\
\left.+(1-\pi) \pi\left\{u\left(c_{1}(i)\right)+u\left(c_{2}(p, i)+c_{1}(p)-c_{1}(i)+R\left[2 y-c_{1}(p)-c_{2}(p, i)\right]\right)\right]\right\} \\
+\pi(1-\pi)\left\{u\left(c_{2}(p, i)\right)+u\left(c_{1}(p)+R\left[2 y-c_{1}(p)-c_{2}(p, i)\right]\right)\right\} \\
+(1-\pi)^{2}\left\{u\left(c_{1}(i)\right)+u\left(2 y-c_{1}(i)\right)\right\}+\lambda\left[c_{1}(p)-\eta\right]
\end{gathered}
$$

where $\lambda \geq 0$ is the Lagrange multiplier associated with the constraint $c_{1}(p) \geq$ $\eta$. Note that the solution to this problem has economic content only as long as $c_{2}(p, i)>c_{1}(i)$ and $c_{2}(i, p)>c_{1}(p)$.

A necessary condition for an optimum for this problem with respect to $c_{1}^{\prime}(p, p)$ is:

$$
u^{\prime}\left(c_{1}(p)+c_{1}^{\prime}(p, p)\right)=u^{\prime}\left(R\left(2 y-c_{1}(p)\right)-c_{1}^{\prime}(p, p)\right) .
$$

Using (35), the necessary conditions for an optimum with respect to $c_{1}(p)$ are:

$$
\left[u^{\prime}\left(c_{1}(p)+c_{1}^{\prime}(p, p)\right)+u^{\prime}\left(c_{1}(p)+R\left[2 y-c_{1}(p)-c_{2}(p, i)\right]\right)\right](R-1)+\lambda=0
$$

and

$$
\lambda\left[c_{1}(p)-\eta\right]=0
$$

Since the term that multiplies $(R-1)$ in $(36)$ is strictly positive and $R>1$, it must the case that $\lambda>0$. Hence, (37) implies that $c_{1}(p)=\eta$. Note that equation (35) then implies:

$$
c_{1}(p)+c_{1}^{\prime}(p, p)=R y-\frac{R+1}{2} \eta
$$

Imposing condition $(38)$ and $c_{1}(p)=\eta$, the maximization problem may alternatively be stated as:

$$
\begin{gathered}
w^{F}(\pi, \sigma)=\max _{c_{2}(p, i), c_{1}(i)} \pi^{2} 2 u\left(R y-\frac{R+1}{2} \eta\right)+ \\
(1-\pi) \pi\left\{u\left(c_{1}(i)\right)+u\left(c_{2}(p, i)+\eta-c_{1}(i)+R\left[2 y-c_{2}(p, i)\right]\right)\right\} \\
+\pi(1-\pi)\left\{u\left(c_{2}(p, i)\right)+u\left(\eta+R\left[2 y-c_{2}(p, i)\right]\right)\right\}+ \\
(1-\pi)^{2}\left\{u\left(c_{1}(i)\right)+u\left(2 y-c_{1}(i)\right)\right\} .
\end{gathered}
$$

If $c_{2}(p, i)>c_{1}(i)$, then the optimal full risk-sharing allocation is characterized by the first-order necessary condition for $c_{2}(p, i)$,

$$
\begin{gathered}
u^{\prime}\left(c_{2}(p, i)+\eta-c_{1}(i)+R\left[2 y-c_{2}(p, i)\right]\right)(1-R)+u^{\prime}\left(c_{2}(p, i)\right) \\
-R u^{\prime}\left(\eta+R\left[2 y-c_{2}(p, i)\right]\right)=0 .
\end{gathered}
$$


Likewise, the first-order necessary condition for $c_{1}(i)$ is given by:

$$
\begin{gathered}
\pi\left\{u^{\prime}\left(c_{1}(i)\right)-u^{\prime}\left(c_{2}(p, i)+\eta-c_{1}(i)+R\left[2 y-c_{2}(p, i)\right]\right)\right\}+ \\
(1-\pi)\left\{u^{\prime}\left(c_{1}(i)\right)-u^{\prime}\left(2 y-c_{1}(i)\right)\right\}=0 .
\end{gathered}
$$

Setting $\eta$ sufficiently close to zero that it can be ignored, conditions (39) and (40) imply that an (approximate) full risk-sharing allocation must satisfy:

$$
\begin{gathered}
u^{\prime}\left(c_{2}(p, i)\right)=R u^{\prime}\left(R\left[2 y-c_{2}(p, i)\right]\right)+(R-1) u^{\prime}\left(c_{2}(p, i)-c_{1}(i)+R\left[2 y-c_{2}(p, i)\right]\right) \\
u^{\prime}\left(c_{1}(i)\right)=(1-\pi) u^{\prime}\left(2 y-c_{1}(i)\right)+\pi u^{\prime}\left(c_{2}(p, i)-c_{1}(i)+R\left[2 y-c_{2}(p, i)\right]\right)
\end{gathered}
$$

assuming that $c_{2}(p, i) \geq c_{1}(i) .{ }^{4}$ In what follows, we evaluate the (approximate) maximum value of this program $w^{F}(\pi, \sigma)$ for $\eta=0$.

Unfortunately, there is no analytical solution for the system in (41)-(42). We can, however, make a number of qualitative observations. To this end, we simplify notation by defining $x \equiv c_{2}(p, i)$ and $z \equiv c_{1}(i)$. Define the function $z=\psi(x)$ implicitly by (41); and likewise define the function $z=\phi(x)$ implicitly by (42). A solution $\left(z^{*}, x^{*}\right)$ satisfies $\psi\left(x^{*}\right)=\phi\left(x^{*}\right)=z^{*}<x^{*}$. By the implicit-function theorem,

$$
\psi^{\prime}(x)=\frac{u^{\prime \prime}(x)+R^{2} u^{\prime \prime}(R[2 y-x])+(R-1)^{2} \hat{u}^{\prime \prime}}{(1-R) \hat{u}^{\prime \prime}}<0
$$

where $\hat{u}^{\prime \prime} \equiv u^{\prime \prime}(x-z+R[2 y-x])$; and

$$
\phi^{\prime}(x)=\frac{(1-R) \hat{u}^{\prime \prime}}{\left(\frac{1}{\pi}\right) u^{\prime \prime}(z)+\left(\frac{1-\pi}{\pi}\right) u^{\prime \prime}(2 y-z)+\hat{u}^{\prime \prime}}<0 .
$$

Clearly, $\left|\psi^{\prime}(x)\right|>\left|\phi^{\prime}(x)\right|$, so that $\psi$ is always "steeper" than $\phi$. These loci are depicted in Figure 1 for the case of where the maximization problem has economic content, i.e., when $x^{*}>z^{*}$.

\footnotetext{
$\overline{4}$ We have a weak inequality here since we are setting $\eta=0$.
} 


\section{Figure 1}

Full Risk-Sharing Solution

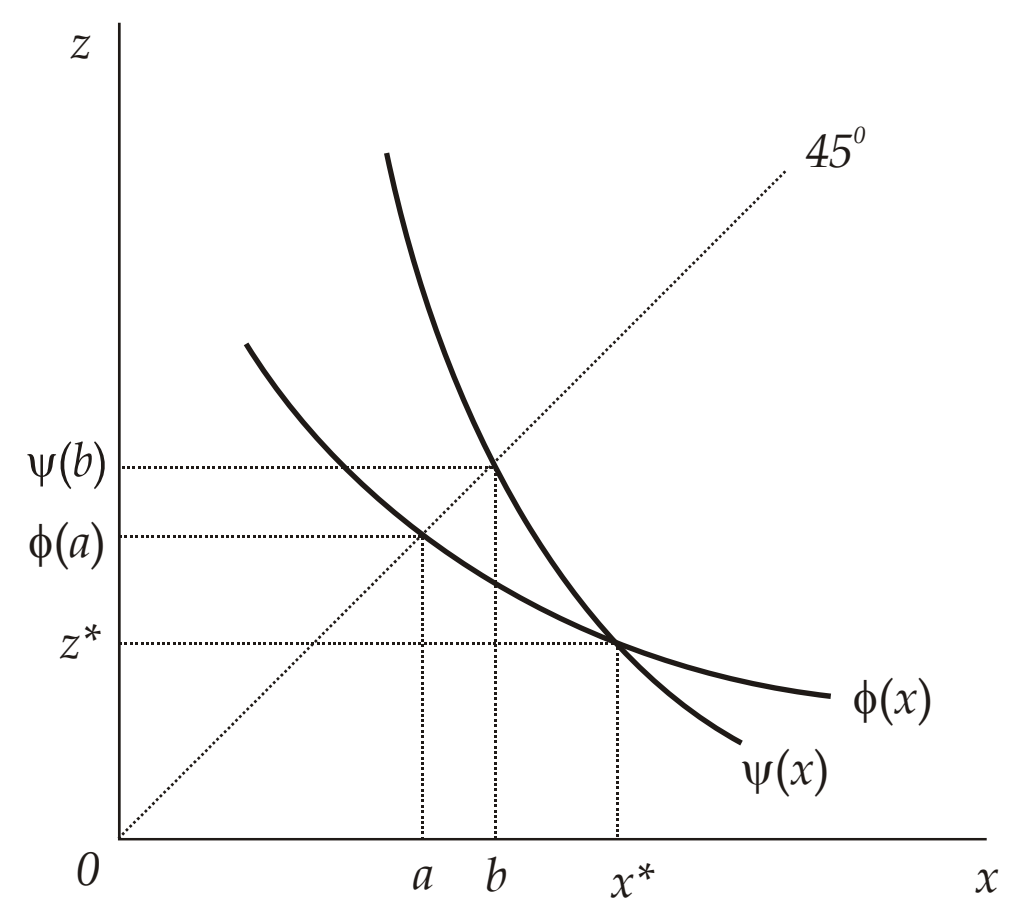

Define a pair of numbers such that $a \equiv \phi(a)$ and $b \equiv \psi(b)$. Using (41) and (42), one can solve explicitly for:

$$
\begin{aligned}
a(\pi, \sigma) & =\frac{2 y}{1+\left[1-\pi+\pi R^{-\sigma}\right]^{\frac{1}{\sigma}}} \\
b(\sigma) & =\frac{2 y}{1+\left[(2 R-1) R^{-\sigma}\right]^{\frac{1}{\sigma}}} .
\end{aligned}
$$

Clearly, $x^{*}>z^{*}$ requires that $b>a$; i.e., see figure 1 .

Observe that $a(\pi, \sigma)$ is strictly increasing in $\pi$, with the implication that higher values of $\pi$ reduce the degree of risk-sharing (i.e., $z^{*}$ approaches $x^{*}$ ). It is easy to establish that there is a threshold $0 \leq \pi^{*}<1$ such that $z^{*} \geq x^{*}$ for all $\pi \leq$ $\pi^{*}$ and $z^{*}<x^{*}$ for all $\pi>\pi^{*}$. The implication here is that for $\pi>\pi^{*}$, the full risk-sharing allocation cannot be optimal. Note that $w^{P}\left(\pi^{*}, \sigma\right)=W^{F}\left(\pi^{*}, \sigma\right)$.

The comparative statics are a little more involved in terms of $\sigma$; but intuitively, one would expect that a higher degree of risk-aversion should (all else held constant) make the full risk-sharing allocation a more likely outcome (this is confirmed in the numerical examples below). 


\subsection{Partial versus Full Risk-Sharing}

Given a parameterization $(\pi, \sigma, R, y)$, we can compute the partial and full risksharing solutions. Define $W^{F}(\pi, \sigma)=w^{F}(\pi, \sigma)$ when conditions (41) and (42) imply that $c_{2}(p, i) \geq c_{1}(i)$; otherwise $W^{F}(\pi, \sigma)=-\infty$. The optimal allocation generates a maximum utility $W(\pi, \sigma)=\max \left\{W^{P}(\pi, \sigma), W^{F}(\pi, \sigma)\right\}$.

Figure 2 plots the date- 1 the allocations $c_{1}(i), c_{2}(p, i)$ and $c_{2}(i, i)$ as a function of parameters. Here, we assume $y=1, R=1.1$ and plot the gross interest rate (date- 1 withdrawal level divided by $y$ ) for $\pi \in\{0.01,0.02, \ldots, 0.99\}$. The coefficient of relative risk-aversion (CRRA) is set to $\sigma=2$.

Figure 2

Date-1 Withdrawal Schedule

CRRA $=2$

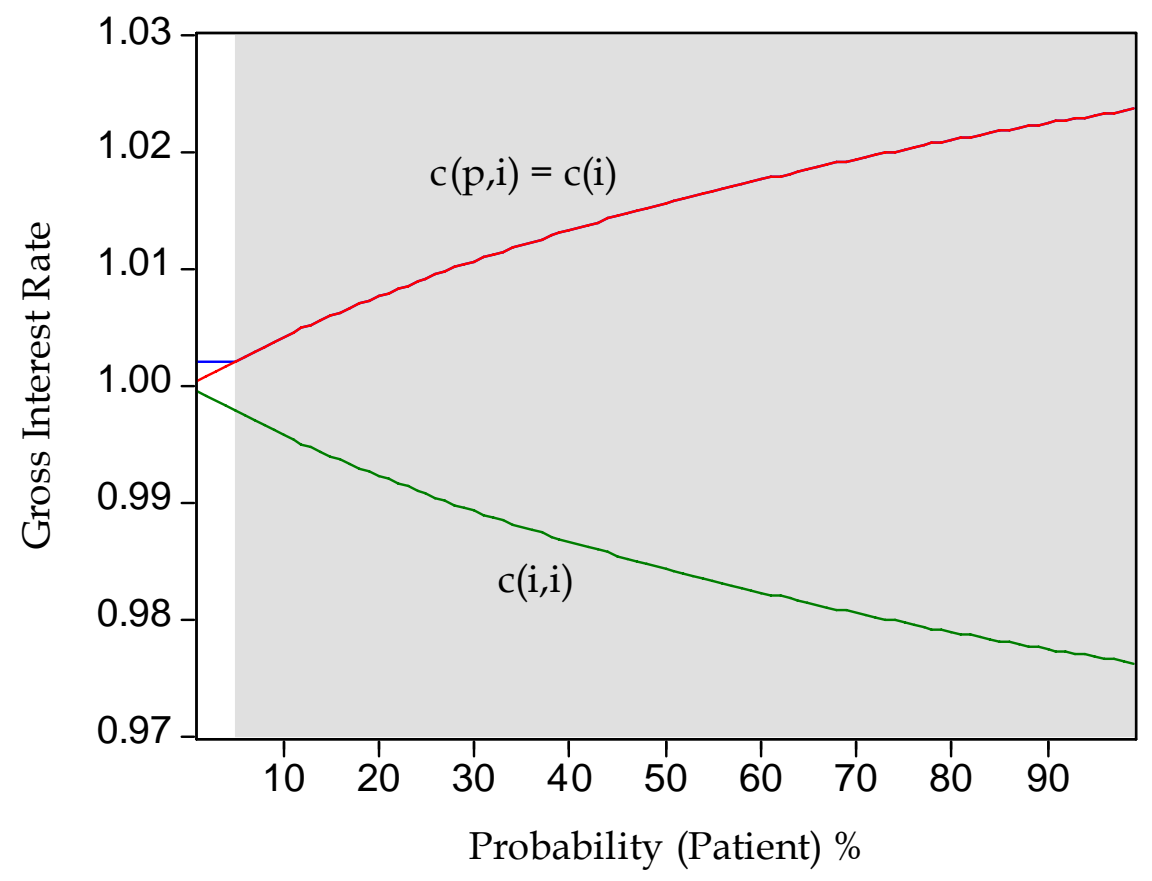

For this parameterization, the partial risk-sharing solution represents the optimal allocation for almost the entire range of $\pi\left(\pi^{*}=0.04\right)$. For very low values of $\pi$, full risk-sharing is optimal but note that the additional return received by the impatient depositors in state $(p, i)$ is trivially small.

As described above, one would expect that the gains to risk-sharing increase 
with the coefficient of relative risk-aversion. Figure 3 verifies that this is indeed the case (the figure considers CRRA $=5$ ). In this case, the full risk-sharing solution is optimal for all $\pi \leq \pi^{*}=0.68$.

Figure 3

\section{Date-1 Withdrawal Schedule}

CRRA $=5$

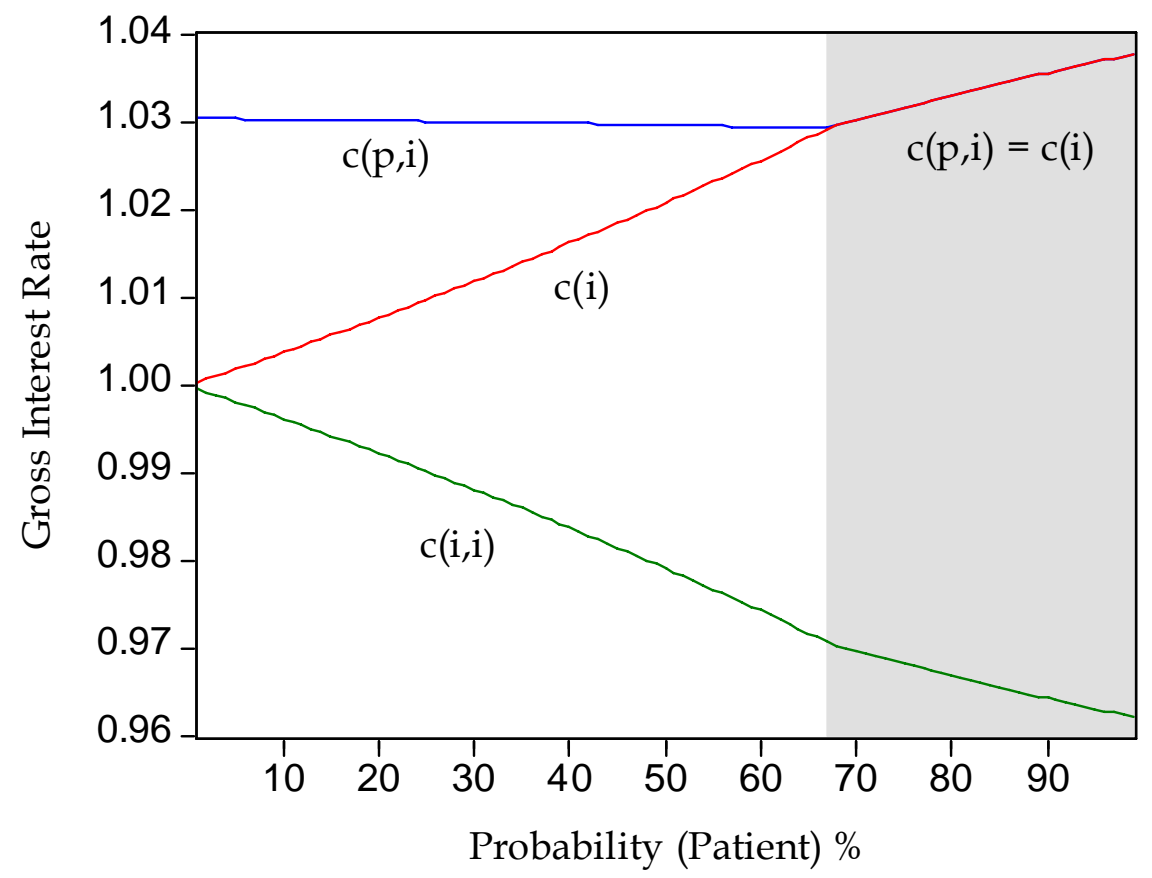

Here it is worth emphasizing that far from simplifying the optimal contractual form, the presence of moral hazard may actually render it even more complicated. In particular, recall that the sophisticated date-1 withdrawal schedule in Green and Lin [5] has the property:

$$
c_{2}(p, i)>c_{1}(i)>c_{2}(i, i)>c_{2}(p, i)=c_{1}(p)=c_{2}(p, p)=0 .
$$

In contrast, when full risk-sharing is optimal in the presence of moral hazard, the optimal date-1 withdrawal schedule has the property:

$$
c_{2}(p, i)>c_{1}(i)>c_{2}(i, i)>c_{2}(p, i)>c_{1}(p) \approx c_{2}(p, p)=0 .
$$

On the other hand, when moral hazard makes full risk-sharing too expensive, the date-1 withdrawal schedule is simplified relative to Green and Lin [5]:

$$
c_{2}(p, i)=c_{1}(i)>c_{2}(i, i)>c_{2}(p, i) \approx c_{1}(p)=c_{2}(p, p)=0 .
$$




\section{Depositor Private Information and Bank-Runs}

To address the issue of the existence of bank-run equilibria, we need to extend the model developed above so that a depositor's type $\omega_{n} \in\{i, p\}$ is private information. The specification of the environment is essentially identical to that described in section 2, except that now the depositor's type is never observable to the either banker or mechanism. The basic structure of the mechanism requires only some minor modifications to accommodate the private information assumption regarding depositors' types.

As described in section 3 , the banker makes a report date- 1 to the mechanism $m_{n}$ after depositor $n-1$ departs and before depositor $n$ arrives. When depositor $n$ arrives he makes a report or announcement $a_{n}$ to the mechanism, where

$$
a_{n}: \Omega_{n} \rightarrow \Omega_{n} \text { for } n=1,2, \ldots, N
$$

where the domain represents the depositors true type. ${ }^{5}$ Note that the mechanism here is similar to the one proposed in Peck and Shell [7]; in particular, we assume that the depositor does not know the previous history of announcements or his place-in-line when he makes his announcement. As stressed by Peck and Shell [7], this property of the mechanism is crucial for entertaining the possibility of a bank-run.

The date- 1 outcome function, $C_{n}(\cdot)$, for depositor $n$ is contingent on the banker's date-1 reports and the depositor's report, i.e.,

$$
C_{n}: \bar{\Omega} \times \Omega_{n} \rightarrow \mathcal{R}_{+} \text {for } n=1,2, \ldots, N
$$

Since that banker is the only agent in the model with a record-keeping device, it is optimal for the mechanism to inform the banker of $a_{n}, n=1, \ldots, N$.

At date- 2 banker and all of the depositors simultaneously make a report. As in section 3 , the banker's date-2 reporting strategy is a function $m^{\prime}: \Omega^{N} \rightarrow \Omega^{N}$ and each depositor announces

$$
a_{n}^{\prime}: \Omega_{n} \rightarrow \Omega_{n} \text { for } n=1,2, \ldots, N
$$

Let $k\left(a_{1}^{\prime}, \ldots, a_{N}^{\prime}\right) \in \mathbb{N}$ denote the number of patient announcements contained in the vector $\left(a_{1}^{\prime}, \ldots, a_{N}^{\prime}\right)$. Again, we stress that the mechanism can only observe $k(\cdot)$ and not the specific configuration of $\left(a_{1}^{\prime}, \ldots, a_{N}^{\prime}\right)$. Hence, a date- 2 allocation or outcome function for depositors is a recommendation $C_{n}^{\prime}(\cdot)$ made contingent on the banker's date-2 report and $k(\cdot)$; i.e.,

$$
C_{n}^{\prime}: \Omega^{N} \times \mathbb{N} \rightarrow \mathcal{R}_{+} \text {for all } n=1,2, \ldots N
$$

5 The mechanism may choose to provide this information to the banker, see below. 
Let $\mathbf{a}=\left(a_{n}, a_{n}^{\prime}\right)_{n=1}^{N}$ represent a strategy profile for the $N$ depositors.

Without loss of generality, we restrict attention to allocations that are truthfully implementable. In keeping with our earlier analysis, we focus on the case where $N=2$.

Assuming that depositors announcement their types truthfully, all of the analysis - and the associated implications - in section 5 remain valid here. In particular, if the allocation is characterized by $c_{2}(p, i)>c_{1}(i)>c_{2}(i, i)$, then $c_{2}(i, p)>c(p)=\varepsilon>0$ is required for banker truth-telling; and if the allocation is characterized by $c_{2}(p, i)=c_{1}(i)>c_{2}(i, i)$, then $c_{2}(i, p)=\eta>0$ is required for banker truth-telling.

Since impatient depositors do not value date- 2 consumption, any optimal allocation will be characterized by $c_{1}^{\prime}(i, i)=c_{2}^{\prime}(i, i)=c_{1}^{\prime}(i, p)=c_{2}^{\prime}(p, i)=0$. As well, an optimal allocation will be characterized by $c_{2}(p, p)=0$ (with $c_{1}(p)=0$ in the partial risk-sharing scenario). Assuming that the banker reveals depositors' announcements truthfully, the truth-telling condition for an impatient depositor is, ${ }^{6}$

$$
\begin{aligned}
& \frac{(1-\pi)^{2}}{2}\left\{u\left(c_{1}(i)\right)+u\left(c_{2}(i, i)\right)\right\}+\pi(1-\pi)\left\{u\left(c_{1}(i)\right)+c_{2}(p, i)\right\} \\
& \frac{(1-\pi)^{2}}{2}\left\{u\left(c_{1}(p)\right)+u\left(c_{2}(i, p)\right)\right\}+\pi(1-\pi) u\left(c_{1}(p)\right) .
\end{aligned}
$$

This condition is always satisfied. First, note that $c_{1}(p)$ is an arbitrarily small number so that for our preferences $u\left(c_{1}(p)\right) \rightarrow-\infty$. Second, note that $u\left(c_{1}(i)\right)+u\left(c_{2}(i, i)\right)>u(y)>u\left(c_{2}(i, p)\right)$ since $c_{1}(i)+c_{2}(i, i)=y$ and $c_{2}(i, p)<y$.

The truth-telling condition for a patient depositor is, ${ }^{7}$

$$
\begin{aligned}
& \frac{\pi^{2}}{2} u\left(R y-\frac{R+1}{2} c_{1}(p)\right)+ \\
& (1-\pi) \pi\left\{u\left(c_{2}(i, p)+R\left(2 y-c_{2}(i, p)-c_{1}(i)\right)\right)+u\left(c_{1}(p)+R\left(2 y-c_{2}(p, i)\right)\right)\right. \\
\geq & \frac{\pi^{2}}{2}\left\{u\left(c_{1}(i)\right)+u\left(c_{2}(p, i)\right)\right\}+(1-\pi) \pi\left\{u\left(c_{1}(i)\right)+u\left(c_{2}(i, i)\right)\right\} .
\end{aligned}
$$

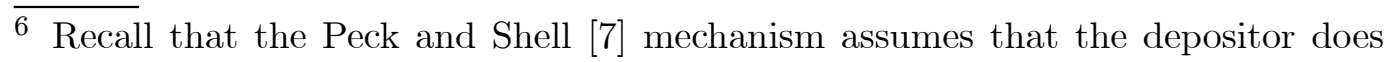
not know his place in line.

7 Since depositors do not know their place in line, it is optimal to deliver to depositors the same utility payoff in state $(p, p)$. 
Allocation $\mathbf{c}$ for the mechanism $(\Omega, \mathbf{c})$ is said to be implementable as a truthtelling equilibrium if conditions (5) and (43) hold.

Suppose that when depositor type is observable, the optimal allocation is characterized by partial risk-sharing; i.e., $c_{2}(p, i)=c_{1}(i)>c_{2}(i, i)$. In this case, it is straightforward to demonstrate that condition (43) is always satisfied with a strict inequality. If, instead, the optimal allocation is characterized by full risk-sharing; i.e., $c_{2}(p, i)>c_{1}(i)>c_{2}(i, i)$, then one can demonstrate (numerically) that condition (43) holds with strict inequality for a wide range of parameter values. ${ }^{8}$ Hence, the optimal allocation when depositor type is observable can be implemented as a truth-telling equilibrium when depositor type is private information. For the preferences considered here, rendering depositor type private information in no way affects our earlier analysis.

Let $\mathbf{c}^{*}$ represent the optimal allocation that can be implemented as a truthtelling equilibrium. Given the mechanism $\left(\boldsymbol{\Omega}, \mathbf{c}^{*}\right)$, do there exist other equilibria, i.e., other than the truth-telling equilibrium? In particular, does there exist a bank-run equilibrium, where the strategy of all depositors is to announce $i$; i.e., $a_{n}=i$ and $a_{n}^{\prime}=i$ for all $\omega_{n}$, and the banker reveals the history of depositor announcements truthfully?

It is straightforward to demonstrate that there does not exist a bank run equilibrium. To see this suppose that all depositors play the bank-run strategy. Then, the bank will rationally announce $m_{n}=i$ for $n=1,2$ and $m^{\prime}=(i, i)$. The banker will announce $m_{1}=i$, instead of the truth $m_{1}=\varnothing$, because this results in a payment to the first depositor of $c_{1}(i, i)<c_{1}(i)$ and the banker's payoff will be $R\left[c_{1}(i)-c_{2}(i, i)\right]>0$, which is higher than the proposed equilibrium payoff of zero. Hence, when depositors play bank-run strategies in the mechanism $\left(\Omega, \mathbf{c}^{*}\right)$, the banker will depart from a truth-telling strategy.

\subsection{Binding Incentive-Compatibility Constraints}

It should be pointed out that if the banker was programed to reveal the depositors' messages truthfully - the standard assumption in the literature - then a bank run equilibrium does not exist for our specification of preferences (Green and Lin [5]). One interesting lesson from Peck and Shell [7] is that if the depositor truth-telling constraint (43) does not bind, then it appears that is impossible to generate a bank-run equilibrium even under the restrictions imposed on their mechanism. To entertain the possibility of a bank-run equilibrium,

\footnotetext{
$\overline{8}$ In fact, we could not find parameters where the condition is violated.
} 
Peck and Shell [7] modify depositor preferences as follows:

$$
U\left(c, c^{\prime}, \omega\right)= \begin{cases}u\left(c+c^{\prime}\right) & \text { if } \quad \omega=p \\ A u(c) & \text { if } \quad \omega=i\end{cases}
$$

where $A>1$. As $A$ is made sufficient large, condition (43) will be violated for the optimal allocation under the assumption that depositor type is observable. Hence, when depositor type is private information, the optimal allocation will have condition (43) binding. Denote the optimal allocation that can be implemented as a truth-telling equilibrium, when condition (43) binds, as $\overline{\mathbf{c}}$. Peck and Shell [7] demonstrate, via an example, that when the depositor truthtelling constraint binds, it is possible to generate a bank-run equilibrium for allocation $\overline{\mathbf{c}}$.

However, note that the "banker" in Peck and Shell [7] is programmed to report truthfully. If we amend the preferences of depositors along the lines of Peck and Shell [7] in our environment so that the optimal allocation implemented under truth-telling has condition (43) binding, then using the same argument above, it would not ever be possible to generate a bank-run equilibrium. That is, if depositors play bank-run strategies, a self-interested banker will depart from truth-telling. Although both Green and Lin [5] and Peck and Shell [7] allude to the possibility that banker moral hazard may open the door to bank runs, we find that, if anything, the introduction of banker moral hazard slams this door shut.

\section{Concluding Remarks}

In this paper, we asked to what extent might moral hazard on the part of a bank might serve to simplify the optimal structure of deposit liabilities and whether such a simplified payment structure might introduce the possibility of bank runs. We found that moral hazard could theoretically render the structure deposit liabilities either more or less complicated relative to those that would emerge in a world of public information. Our numerical results suggest that simple contracts emerge under a wide range of empirically plausible parameter values. However, whether or not the payment structure turns out to be simple, it appears that the introduction of moral hazard actually eliminates the possibility of a bank-run equilibrium. 


\section{References}

[1] D. Andolfatto, E. Nosal and N. Wallace, The role of independence in the Green-Lin Diamond-Dybvig Model. Forthcoming, J. Econ. Theory.

[2] C. Calomiris and C. Kahn, The role of demandable debt in structuring optimal banking arrangements. Amer. Econ. Review 81 (1991), pp. 497-513.

[3] D. Diamond and P. Dybvig, Bank runs, deposit insurance, and liquidity. J. Polit. Econ. 91 (1983), pp. 401-419.

[4] D. Diamond, Financial intermediation and delegated monitoring, Rev. Econ. Studies 51 (1984), pp. 393-414.

[5] E. Green and P. Lin, Implementing efficient allocations in a model of financial intermediation, J. Econ. Theory 109 (2003), pp. 1-23.

[6] S. Krasa and A.P. Villamil, Monitoring the monitor: An incentive structure for a financial intermediary. J. Econ. Theory 57 (1992), pp. 197-221.

[7] J. Peck and K. Shell, Equilibrium Bank Runs, J. Polit. Econ. 111 (2003), pp. 103-123.

[8] N. Wallace, Another attempt to explain an illiquid banking: the DiamondDybvig model with sequential service taken seriously. Fed. Reserve Bank Minneapolis Quart. Rev. 12 (1988), pp. 3-16. 